\title{
Evaluation of Surgical Completeness in Endoscopic Total Thyroidectomy with Central Neck Dissection via a Unilateral Axillo-Breast Approach Compared with Bilateral Axillo-Breast and Open Approach
}

\author{
Ik Joon Choi ${ }^{1 *}$, Ilhan Lim ${ }^{2 *}$, Byeong-Cheol Lee ${ }^{1}$, Guk Haeng Lee ${ }^{1}$, and Myung-Chul Lee ${ }^{1}$ \\ ${ }^{1}$ Departments of Otorhinolaryngology-Head and Neck Surgery, ${ }^{2}$ Nuclear Medicine, Korea Cancer Center Hospital, \\ Korea Institute of Radiological and Medical Sciences, Seoul, Korea
}

\begin{abstract}
양측 액와유방 접근법과 개방성 접근법과의 비교를 통한 일측 액와유방 접근 내시경 갑상선 전 절제술과 중심 경부 절제술의 수술적 완전성에 대한 평가
\end{abstract}

최익준 ${ }^{*} \cdot$ 임일한 ${ }^{*} \cdot$ 이병철 ${ }^{1} \cdot$ 이국행 ${ }^{1} \cdot$ 이명철

한국원자력의학원 원자력병원 이비인후-두경부외과, ${ }^{1}$ 핵의학과 ${ }^{2}$

\author{
Received July 17, 2018 \\ Revised September 21, 2018 \\ Accepted October 16, 2018 \\ Address for correspondence \\ Myung-Chul Lee, MD, PhD \\ Department of Otorhinolaryngology- \\ Head and Neck Surgery, \\ Korea Cancer Center Hospital, \\ Korea Institute of Radiological and \\ Medical Sciences, \\ 75 Nowon-ro, Nowon-gu, \\ Seoul 01812, Korea \\ Tel $+82-2-970-2173$ \\ Fax +82-2-970-2450 \\ E-mail entdok@gmail.com \\ *These authors equally contributed \\ to this work.
}

Background and Objectives The aim of this study was to evaluate surgical completeness in endoscopic total thyroidectomy with central neck dissection via unilateral axillo-breast approach (UABA) compared with bilateral axillo-breast (BABA) and open approach (OA) by means of the radioactive iodine uptake (RAIU) ratio and thyroglobulin (Tg) of remnant thyroid. Subjects and Method From July 2010 to March 2013, 82 patients who had underwent total thyroidectomy with central neck dissection and postoperative radioactive iodine (RAI) ablation for papillary thyroid carcinoma were enrolled. Of these patients, 27 patients underwent UABA, 24 patients BABA, and 31 patients OA. Clinicopathologic data, surgical outcome, stimulated Tg and RAIU ratio on the first postoperative RAI ablation scan were compared among 3 groups. Results Patients in the endoscopic surgery groups (UABA, BABA) were younger than those in the OA groups. Invasiveness such as operation time, postoperative pain, and drain amount in UABA was less than that in BABA and severer than that in OA. Other variables regarding clinicopathologic and surgical data were not significantly different. Stimulated Tg and RAIU ratio did not show significant differences among 3 groups ( $p=0.659$ and $p=0.664$ ).

Conclusion The completeness of UABA was comparable with that of BABA and OA. The UABA may be a safe option for patients who need endoscopic thyroidectomy for papillary thyroid carcinoma. Korean J Otorhinolaryngol-Head Neck Surg 2018;61(12):697-701

Key Words Bilateral axillo-breast approach · Completeness · Endoscopy · Thyroidectomy · Unilateral axillo-breast approach.

\section{서 론}

고분화 갑상선암의 발생률은 대한민국을 포함하여 세계적

This is an Open Access article distributed under the terms of the Creative Commons Attribution Non-Commercial License (https://creativecommons.org/licenses/by-nc/4.0) which permits unrestricted non-commercial use, distribution, and reproduction in any medium, provided the original work is properly cited.
으로 급격하게 증가하고 있다. 이러한 갑상선암은 특히 여성 에서 대부분 발생하고, 그중에서도 젊은 여성 환자들이 많이 늘어나고 있다.,2) 다른 부위의 암들에 비해서 갑상선암의 예 후는 아주 좋기 때문에 사망률, 재발률도 중요하지만 치료 후 의 삶의 질에 대한 관심이 높다. 특히 수술 후 목의 앞부분에 남는 절개선은 미용적으로 좋지 않기 때문에 이를 피하기 위 
한 시술이 요구되고 있다. ${ }^{3)}$

Hüscher 등 ${ }^{4}$ 이 1997년에 처음으로 목의 절개선을 없앤 내 시경적 갑상선 술기를 발표한 후부터 많은 내시경적 수술법 이 개발되고 있다. 이러한 내시경적 술기는 갑상선에 접근하 는 위치와 방향에 따라서 크게 경부, 흥부, 액와, 유방, 후이 개, 또는 구강 접근법으로 나뉘게 되고, 또 이러한 접근법들의 조합으로 다양한 방법이 소개되었다. ${ }^{5-9)}$ 본 저자들도 2012년 에 가스를 이용한 일측 액와-유방 접근법(unilateral axillobreast approach with gas insufflation, UABA)을 이용한 새 로운 내시경 갑상선 절제술을 보고한 바 있다. ${ }^{10)}$ 이러한 내시 경적 술식들은 수술의 초기 결과와 합병증 등에 대해서는 기 존의 경부 절제술과 비슷한 정도의 성적을 보여주고 있다. ${ }^{11,12)}$ 하지만 내시경적 수술이 수술의 완전성 면에서 경부절개술에 비해서 떨어져 잔여 갑상선 조직이 수술 후 남지 않을까 하는 걱정이 있어 왔고 이에 대한 연구는 많지 않은 실정이다. ${ }^{13-15)}$

본 연구의 목적은 혈중 티로글로불린(thyroglobulin, $\mathrm{Tg}$ )과 방사선 요오드 섭취율을 이용하여 새로운 내시경 수술법인 $\mathrm{UABA}$ 갑상선 절제술의 수술적 완전성을 기존 내시경 수술법 인 양측 액와유방 접근법(bilateral axillo-breast approach, $\mathrm{BABA}$ )과 개방성 경부 절개술(open approach, $\mathrm{OA}$ )과 비교하 여 평가하는 것이다.

\section{대상 및 방법}

\section{대 상}

2010년 7월에서 2013년 3월까지 한국원자력의학원에서 분 화 갑상선암으로 갑상선 전 절제술, 중심 경부 절제술과 술 후 방사선 동위원소 절제술을 받은 총 82 명의 환자를 대상으로 하였다(IRB No. 2018-07-004). 이 중에서 27명은 UABA, 24 명은 $\mathrm{BABA}, 31$ 명은 $\mathrm{OA}$ 수술법으로 수술을 받았다. 수술 전 에 환자들에게 각각의 수술법에 대해서 자세히 설명하고, 담 당 의사와 환자가 충분히 상의한 다음 수술법을 결정하였다. 각각의 수술법을 비교하려는 의도가 없었기 때문에 무작위법
으로 수술을 선택하지는 않았다. 변종 분화갑상선암, 저분화 또는 미분화 갑상선암, 갑상선 엽절제술만 한 경우, 외측 경부 절제술을 같이 한 경우, 혈청 $\mathrm{Tg}$ 항체 양성, 그리고 이전에 경 부 방사선 조사를 받은 적이 있는 환자들은 제외하였다.

\section{수술법}

모든 수술은 1 인의 술자에 의해서 행해졌다. UABA와 $\mathrm{BABA}$ 를 시행 받은 군들은 각각의 원저에 기술된 대로 수술 을 시행하였다. ${ }^{10,16)} \mathrm{UABA}$ 는 갑상선 전 절제술과 중심 경부 절 제술을 위해서 양측으로 시행하였다. OA 군에서는 경부를 신전시킨 후 윤상연골과 흥골절흔(sternal notch) 사이에 4 5 $\mathrm{cm}$ 정도의 피부 횡절개를 가하고 개방성 갑상선 전 절제술과 중심 경부 절제술을 시행하였다. ${ }^{17)}$

\section{방사선 동위원소 잔여 갑상선 조직 절제(Radioactive iodine ablation of remnant thyroid)}

환자들은 3주간 티록신 복용을 중지하고 저요오드식으로 갑상선 자극 호르몬의 분비를 자극한 상태에서 혈중 갑상선 자극호르몬(thyroid stimulating hormone, TSH), 자극(stimulated) $\mathrm{Tg}$, 항 $\mathrm{Tg}$ 항체를 측정하고 수술 후 잔여 갑상선 조 직과 암 절제를 위해서 I-131(100 200 mCi)을 투여받았다. 투여 48시간 후에 I-131 전신 스캔을 시행하였다.

\section{술 후 잔여 갑상선 조직의 측정}

첫 번째 방사선 동위원소 갑상선 절제술 후에 방사선 동위 원소의 섭취를 측정하여 각각의 치료군 사이의 차이를 확인 하였다. 직사각형 관심 영역(region of interest)을 목에서 갑 상선 잔여 조직이 있는 부위를 포함하게 그린 다음, 같은 크 기의 또 하나의 관심 영역을 기준이 되는 뇌 부분에 그린다 (Fig. 1). 기준이 되는 뇌 부위는 뇌 중앙부에 방사선 동위원 소 섭취가 가장 적은 부분으로 정하였다. 두 영역에서 계수를 측정하여 두 계수 간의 비율(radioactive iodine uptake ratio, RAIU ratio)을 계산하고 이것으로 잔여 갑상선 조직의 양을
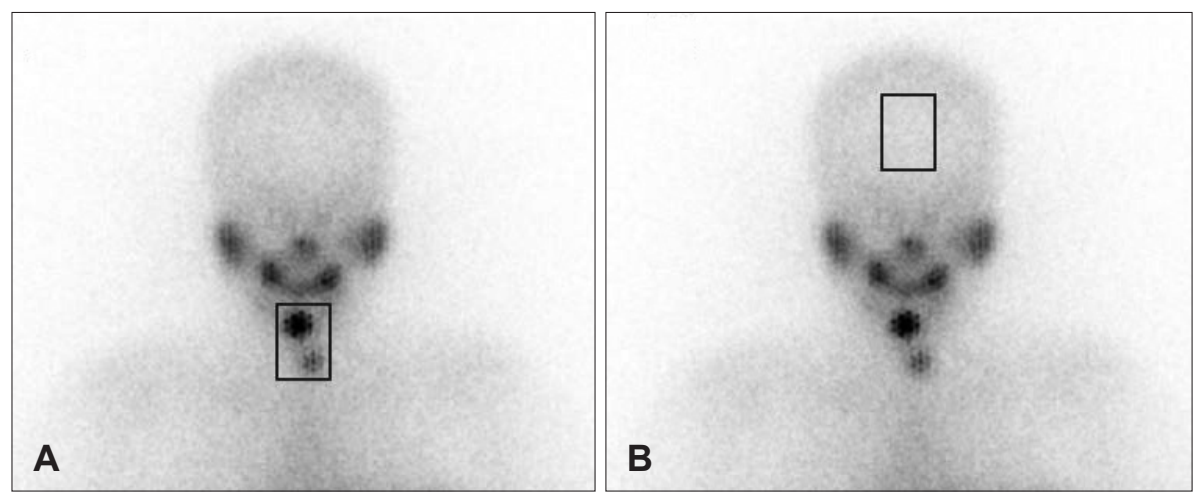

Fig. 1. Measurement of ROI count. ROI count at remnant thyroid (A). $\mathrm{ROI}$ count at brain area as a reference region (B). ROI: region of interest. 
결정하였다. 보조적으로 자극 $\mathrm{Tg}$ 와 $\mathrm{TSH}$, 초 치료를 위해서 사 용된 방사선 동위원소 용량도 각 군 간의 비교에 이용하였다.

\section{통계 분석}

$\chi^{2}$ test를 이용하여 세 군 간의 임상병리학적 자료를, Kruskal-Wallis test, Mann Whitney U test를 이용하여 수술 결과, $\mathrm{RAIU}$ ratio, 자극 $\mathrm{Tg}, \mathrm{TSH}$, 동위원소 용량을 통계학적으로 비 교 분석하였다. SPSS 17.0 for Windows(SPSS Inc., Chicago, $\mathrm{IL}, \mathrm{USA}$ )를 통계분석에 이용하였고, $p<0.05$ 인 경우 통계적 으로 유의하다고 판단하였다.

\section{결 과}

성별, 나이, 종양의 크기, 병리조직학적 특징들(histologic type, multifocality, extrathyroidal extension, lymph node metastasis)을 Table 1에 요약 정리하였다. 세 군의 모든 환자 들이 여자였다. 내시경으로 수술한 군들(UABA, BABA)이

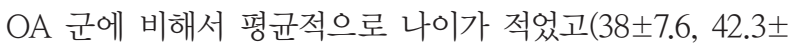
8.9 vs. 51.2 \pm 8.41 ) 이는 통계적으로 유의한 차이를 보였다. 각 군 간의 술 후 병리학적 결과는 통계학적 차이를 보이지 않 았다.

수술의 결과를 Table 2에 기술하였다. 수술 시간, 수술 후

Table 1. Clinicopathologic characteristics

\begin{tabular}{|c|c|c|c|c|}
\hline Characteristics & $\operatorname{UABA}(n=27, \%)$ & BABA $(n=24, \%)$ & $\mathrm{OA}(\mathrm{n}=31, \%)$ & $p$ \\
\hline $\operatorname{Sex}(M: F)$ & $0: 27$ & $0: 24$ & $0: 31$ & \\
\hline Age (years) & $38 \pm 7.6(23-53) *$ & $42.3 \pm 8.9(29-68)^{*}$ & $51.2 \pm 8.41(38-67)^{*}$ & 0.006 \\
\hline Size of primary tumor (cm) & $1.12 \pm 0.57(0.1-2.2) *$ & $0.9 \pm 0.47(0.1-3.5)^{*}$ & $0.9 \pm 1.18(0.2-3.5)^{*}$ & 0.271 \\
\hline \multicolumn{5}{|l|}{ Histologic type } \\
\hline Papillary carcinoma & $27(100)$ & $24(100)$ & $31(100)$ & \\
\hline Multifocality & $15(55.6)$ & $17(70.8)$ & $16(51.6)$ & 0.402 \\
\hline Extrathyroid extension & $12(44.4)$ & $14(58.3)$ & $18(58.1)$ & 0.425 \\
\hline Lymph node metastasis (level 6) & $17(63.0)$ & $14(58.3)$ & $13(41.9)$ & 0.449 \\
\hline
\end{tabular}

*data are expressed in mean \pm standard deviation (range). UABA: unilateral axillo-breast approach, BABA: bilateral axillo-breast approach, OA: open approach

Table 2. Surgical outcomes

\begin{tabular}{|c|c|c|c|c|}
\hline Outcomes & $\operatorname{UABA}(n=27, \%)$ & BABA $(n=24, \%)$ & $O A(n=31, \%)$ & $p$ \\
\hline Operative time (minute) & $172.46 \pm 32.21^{*}$ & $201.32 \pm 54.41^{*}$ & $103.13 \pm 31.21^{*}$ & $<0.001$ \\
\hline \multicolumn{5}{|l|}{ Visual analogue scale for pain $(1-5)$} \\
\hline Postoperative 1 day & $2.34 \pm 0.75^{*}$ & $3.65 \pm 1.02^{*}$ & $2.15 \pm 1.01^{*}$ & $<0.001$ \\
\hline Postoperative 3 day & $2.23 \pm 0.81^{*}$ & $2.78 \pm 0.79^{*}$ & $1.55 \pm 0.64^{*}$ & $<0.001$ \\
\hline Amount of drain for 3 days $(\mathrm{mL})$ & $163.58 \pm 42.12^{*}$ & $210.14 \pm 65.6^{*}$ & $120.32 \pm 45.47^{*}$ & $<0.001$ \\
\hline \multicolumn{5}{|l|}{ Postop. complications } \\
\hline Temporary VCP & $2(7.4)$ & $4(16.6)$ & $1(3.2)$ & 0.071 \\
\hline Permanent VCP & $0(0)$ & $1(4.1)$ & $0(0)$ & 0.761 \\
\hline Seroma & $0(0)$ & $1(4.1)$ & $0(0)$ & 0.761 \\
\hline Temporary hypoparathyroidism & $3(11.1)$ & $4(16.6)$ & $3(9.7)$ & 0.098 \\
\hline Permanent hypoparathyroidism & $0(0)$ & $1(4.1)$ & $0(0)$ & 0.761 \\
\hline
\end{tabular}

*data are expressed in mean \pm standard deviation. VCP: vocal cord paralysis, UABA: unilateral axillo-breast approach, BABA: bilateral axillo-breast approach, OA: open approach

Table 3. Comparison of remnant thyroid

\begin{tabular}{lcccc}
\hline \multicolumn{1}{c}{ Indices of remnant thyroid } & UABA $(n=27)$ & BABA $(n=24)$ & OA $(n=31)$ & $p$ \\
\hline RAIU ratio & $15.71 \pm 13.7$ & $13.67 \pm 11.0$ & $13.26 \pm 13.1$ & 0.656 \\
Stimulated Tg level $(\mathrm{ng} / \mathrm{mL})$ & $2.89 \pm 3.83$ & $3.6 \pm 6.6$ & $2.92 \pm 5.02$ & 0.647 \\
TSH level $(\mu \mathrm{lU} / \mathrm{mL})$ & $65.9 \pm 25.8$ & $68.7 \pm 24.8$ & $68.4 \pm 23.5$ & 0.712 \\
Dose of RAl ablation $(\mathrm{mCi})$ & $161.2 \pm 26.8$ & $164.6 \pm 24.1$ & $155.0 \pm 29.0$ & 0.471 \\
\hline
\end{tabular}

All data are expressed in mean \pm standard deviation. RAIU: radioactive iodine uptake, Tg: thyroglobulin, TSH: thyroid stimulating hormone, RAI: radioactive iodine, UABA: unilateral axillo-breast approach, BABA: bilateral axillo-breast approach, OA: open approach 
통증, 드레인양은 내시경 그룹(UABA, BABA)이 통계적으로 유의하게 길고 심하고, 양이 많았다. 갑상선 수술의 대표적인 합병증인 일시적, 영구적 성대 마비, 장액종(seroma)과 일시 적, 영구적 갑상선 기능 저하증의 빈도는 세 군 간에 통계적 으로 유의한 차이는 없었다.

Table 3에서 수술 후 잔여 갑상선 양을 비교하였다. RAIU ratio는 $\mathrm{UABA}$ 군에서 $15.71 \pm 13.7, \mathrm{BABA}$ 군에서 $13.67 \pm$ 11.0 , 그리고 $\mathrm{OA}$ 군에서 $13.26 \pm 13.1$ 로 통계적으로 유의한 차이는 보이지 않았다 $(p=0.656)$. RAIU ratio를 두 군 간에 각각 비교를 해 보았더니 1) UABA vs. BABA, $p=0.843,2$ ) $\mathrm{UABA}$ vs. $\mathrm{OA}, p=0.562,3) \mathrm{BABA}$ vs. $\mathrm{OA}, p=0.332$ 로 통계 적으로 유의한 차이는 없었다. 첫 번째 방사선 동위원소 갑상 선 절제술을 시행하는 날에 측정한 자극 $\mathrm{Tg}$ 수치는 $\mathrm{UABA}$ 군에서 $2.89 \pm 3.83 \mathrm{ng} / \mathrm{mL}, \mathrm{BABA}$ 군 $3.6 \pm 6.6 \mathrm{ng} / \mathrm{mL}$, 그리 고 $\mathrm{OA}$ 군은 $2.92 \pm 5.02 \mathrm{ng} / \mathrm{mL}$ 로 통계적으로 차이가 없었다 $(p=0.647)$. 자극 $\mathrm{Tg}$ 수치도 두 군 간에 각각 비교를 하니 1) UABA v.s BABA, $p=0.842$, 2) UABA vs. OA, $p=0.395,3$ ) $\mathrm{BABA}$ vs. $\mathrm{OA}, p=0.508$ 로 통계적으로 유의한 차이는 없었 다. 같은 날 측정한 TSH 수치는 $\mathrm{UABA}, \mathrm{BABA}$, 그리고 $\mathrm{OA}$ 군에서 각각 $65.9 \pm 25.8,68.7 \pm 24.8,68.4 \pm 23.5 \mu \mathrm{IU} / \mathrm{mL}$ 으로 비슷하였다 $(p=0.712)$. 수술 후 방사선 동위원소 절제술을 위 해 사용된 방사선 용량은 $\mathrm{UABA}, \mathrm{BABA}$, 그리고 $\mathrm{OA}$ 군에 서 각각 $161.2 \pm 26.8,164.6 \pm 24.1$, 그리고 $155.0 \pm 29.0 \mathrm{mCi}$ 로 통계적으로 차이가 없었다 $(p=0.471)$.

\section{고 찰}

본 연구의 목적은 본원에서 개발하여 시행하고 있는 UABA 갑상선 절제술의 수술적 완전성을 기존에 시행하던 $\mathrm{BABA}$ 및 $\mathrm{OA}$ 갑상선 절제술과 비교하여 확인하는 것이었다.

$\mathrm{UABA}$ 는 2012년도에 저자들이 개발하여 시행하고 있는 방 법으로 기존에 많이 시행되어 오던 경액와 접근법(transaxillary approach)을 변형하여 액와에서부터 갑상선까지 피판을 거 상 하지 않고, 트로카를 통해 접근하여 $\mathrm{CO}_{2}$ 가스를 주입한 다음 갑상선 절제술을 시행하는 방식이다.10) $\mathrm{UABA}$ 는 경부 의 상처를 없애고, 기존의 넓은 피판 거상 범위를 줄여서 수 술 후 통증이나 드레인양을 줄이고, 합병증도 줄이는 등 수술 의 결과 면에서 좋았지만 수술의 완전성 면은 아직 평가되지 않았다.

갑상선 전 절제술로 모든 갑상선 조직을 제거하는 것은 현 실적으로 불가능하여 대부분의 경우 수술 후에 어느 정도 갑 상선 조직이 남게 된다. ${ }^{18)}$ 이러한 잔여 갑상선 조직의 양을 확 인하는 방법으로는 혈청 $\mathrm{Tg}$, 초음파, 방사선 동위원소 섭취
율(RAIU), 방사선 동위원소 섭취 비율(RAIU ratio), 방사선 동위원소 전신 스캔 등이 있다. ${ }^{18,19)}$ 본 연구에서 수술의 완전 성을 평가하는 지표로는 자극 $\mathrm{Tg}$ 와 첫 번째 방사선 동위원 소 갑상선 절제술 후 스캔에서 측정한 잔여 갑상선 조직의 상대 방사선 동위원소 섭취 비율(RAIU ratio)을 사용하였다. 자극 혈청 $\mathrm{Tg}$ 수치와 방사선 동위원소 스캔에서 방사선 섭취 는 갑상선 전 절제술 후에 수술의 완전성을 평가하는 신뢰할 수 있는 지표로 알려져 있다. ${ }^{13,20)}$ 방사선 동위원소가 혈액 뇌 장벽을 통과하지 못하기 때문에 상대 방사선 동위원소 섭취 비율에서 기준점을 뇌로 정하고 갑상선 부위의 스캔에서의 계수와 뇌에서의 계수의 비(RAIU ratio)를 구하여 세군 간에 비교하였다. ${ }^{13)}$ 이 RAIU ratio는 절대값이 아니고 상대적인 비 율이긴 하지만 한 기관에서 같은 방식으로 방사선 동위원소 치료한 환자군을 대상으로 했기 때문에 수술법의 완전성을 비교하기에는 적합하다.

핵의학적 방법으로 내시경과 개방성 갑상선 절제술의 완전 성을 비교한 기존의 연구들에서는 두 방법이 비슷한 정도의 완전성을 보인다고 보고하였다. ${ }^{13,18)}$ 하지만 Lee 등슨 근 경액 와 접근법으로 시행한 갑상선 절제술의 술 후 첫 방사선 동 위원소 갑상선 절제술 후 RAIU ratio가 개방성 갑상선 절제 술의 수치보다 크다고 보고하였다. 이는 경액와 접근법의 특 성상 일측 갑상선을 제거한 다음 동측의 같은 액와절개창을 통해서 기관(trachea)을 넘어 반대측 수술을 해야 하는데 이 때 반대측 갑상선엽을 완전히 절제하는 것이 어렵기 때문이 라고 분석하였다. ${ }^{15)}$

본 연구에서는 $\mathrm{UABA}$ 수술법을 $\mathrm{BABA}$ 및 $\mathrm{OA}$ 수술법과 비 교하였다. 내시경적 수술법(UABA, BABA)을 채택한 환자 들의 나이가 상대적으로 적다는 것을 제외하고는 환자들의 특징은 세 군 간의 통계적 차이가 없었다(Table 1). 수술의 결과를 보면 내시경적 수술법이 수술의 특성상 OA보다는 수 술 시간이 길고 통증이 심하고, 드레인 양이 많아서 기존의 보고들과 유사한 결과를 보였고, 내시경적 수술법 사이에서 는 $\mathrm{UABA}$ 가 $\mathrm{BABA}$ 보다 통증이나 드레인 양이 적었다. 이 는 $\mathrm{BABA}$ 를 시행할 때 유륜 주위에 절개선을 넣고 긴 기구 를 이용하여 가슴 피부 아래 공간을 유륜부터 쇄골 위쪽까 지 넓게 박리한 다음에 트로카를 넣는 반면, $\mathrm{UABA}$ 를 할 때 는 가슴쪽 트로카를 쇄골 근처까지 바로 집어넣고 수술을 시작하기 때문이라고 생각된다. 수술의 합병증은 세 군 간의 차이는 없었다(Table 2).

수술의 완전성을 비교하는 RAIU ratio와 자극 $\mathrm{Tg}$ 는 세 군 간에 통계적으로 유의한 차이를 보이지는 않았다. $\mathrm{OA}$ 는 갑상선의 노출이 아주 뛰어나고, 수술 시야가 양측 대칭으로 훌륭해서 후두신경과 부갑상선을 잘 보전하면서 남은 갑상 
선 조직을 최소화할 수 있기 때문에 갑상선 절제술의 표준이 라 할 수 있다. ${ }^{18)} \mathrm{BABA}$ 접근법은 기존의 여러 보고에서 수술 의 완전성 면에서 검증이 되었다. ${ }^{13,21)}$ 본 연구에서 $\mathrm{UABA}$ 접근 법은 기존에 완전성 면에서 검증된 $\mathrm{BABA}, \mathrm{OA}$ 와 비슷한 정 도의 수술적 완전성을 보였다. UABA 접근법이 경액와 접근 법의 변형인데도 불구하고, 기존의 경액와 접근법의 보고와 ${ }^{14,15)}$ 다르게 술 후 첫 방사선 동위원소 치료 시 RAIU ratio 결과가 좋은 것은 갑상선 전 절제술을 할 때 경액와 접근법과 달리 양측으로 접근함으로써 반대측 갑상선엽의 절제가 무리 없이 이루어지기 때문이다.

본 연구에는 몇 가지 한계가 있다. 첫째, 전체 환자군의 크 기가 크지 않고 단일기관에서의 연구라서 통계적인 검증력이 크지 않다. 전향적으로 환자수를 더 늘리고 다기관연구를 통 해 비열등성 검사(noninferiority test)를 시행해야 기존의 수 술법들과의 완전성 면에서의 비교가 통계적으로 힘을 더 얻 을 것으로 생각된다. 둘째, 후향적 비무작위배정 연구이기 때 문에 선택 치우침(selection bias)이 있을 수 있다. 이를 최대한 극복하기 위하여 환자들에게 세 가지 수술법의 장단점에 대 해서 자세히 설명하고, 충분히 질문을 들어주고 대답을 충실 히 한 다음 환자에게 수술법의 결정을 맡기긴 했지만 의사나 환자의 주관이 어느 정도는 들어갈 수밖에 없다. 이는 후향 적 연구의 태생적 한계로 추후 전향적 무작위 배정 디자인의 연구를 시행해야 이런 문제를 극복할 수 있을 것으로 생각된 다. 셋째, 본원에서 개발한 내시경 갑상선 수술의 완전성을 평가하는 방법으로 수술 후 방사선 동위원소 치료 시 혈액검 사와 핵의학적 검사를 선택하였는데 가장 확실한 것은 개방 성 갑상선 수술에 대한 기존의 연구와 비슷한 정도로 장기간 추적 관찰기간을 거쳐서 생존율과 재발률 등을 확인하는 것 이다. 추후 연구에서는 혈액검사, 핵의학 검사뿐만 아니라 더 긴 추적관찰기간을 통해서 생존율과 재발률 등을 확인하는 작업이 필요하겠다.

결론적으로, $\mathrm{UABA}$ 접근법을 통한 갑상선 절제술은 수술 의 합병증과 완전성 면에서 기존의 $\mathrm{BABA}$ 및 개방성 접근법 과 차이가 나지 않았다. 그러므로 UABA 접근법은 갑상선암 으로 내시경 수술을 필요로 하는 환자들에게 수술의 합병증 및 완전성 면에서 안전한 옵션이라고 생각된다.

\section{REFERENCES}

1) Sanabria A, Kowalski LP, Shah JP, Nixon IJ, Angelos P, Williams $\mathrm{MD}$, et al. Growing incidence of thyroid carcinoma in recent years: factors underlying overdiagnosis. Head Neck 2018;40(4):855-66.

2) Jung KW, Won YJ, Oh CM, Kong HJ, Lee DH, Lee KH; Community of Population-Based Regional Cancer Registries. Cancer Statistics in Korea: incidence, mortality, survival, and prevalence in 2014. Cancer Res Treat 2017;49(2):292-305.
3) Kitagawa W, Shimizu K, Akasu H, Tanaka S. Endoscopic neck surgery with lymph node dissection for papillary carcinoma of the thyroid using a totally gasless anterior neck skin lifting method. J Am Coll Surg 2003;196(6):990-4.

4) Hüscher CS, Chiodini S, Napolitano C, Recher A. Endoscopic right thyroid lobectomy. Surg Endosc 1997;11(8):877.

5) Ohgami M, Ishii S, Arisawa Y, Ohmori T, Noga K, Furukawa T, et al. Scarless endoscopic thyroidectomy: breast approach for better cosmesis. Surg Laparosc Endosc Percutan Tech 2000;10(1):1-4.

6) Ikeda Y, Takami H, Niimi M, Kan S, Sasaki Y, Takayama J. Endoscopic thyroidectomy and parathyroidectomy by the axillary approach. A preliminary report. Surg Endosc 2002;16(1):92-5.

7) Miccoli P, Bellantone R, Mourad M, Walz M, Raffaelli M, Berti P. Minimally invasive video-assisted thyroidectomy: multiinstitutional experience. World J Surg 2002;26(8):972-5.

8) Terris DJ, Singer MC, Seybt MW. Robotic facelift thyroidectomy: patient selection and technical considerations. Surg Laparosc Endosc Percutan Tech 2011;21(4):237-42.

9) Anuwong A. Transoral endoscopic thyroidectomy vestibular approach: a series of the first 60 human cases. World J Surg 2015;40(3):491-7.

10) Lee MC, Mo JA, Choi IJ, Lee BC, Lee GH. New endoscopic thyroidectomy via a unilateral axillo-breast approach with gas insufflation: preliminary report. Head Neck 2013;35(4):471-6.

11) Lee MC, Park H, Choi IJ, Lee BC, Lee GH. Comparative study of a gasless transaxillary approach versus a bilateral axillo-breast approach for endoscopic thyroidectomy in a single institute. Head Neck 2013; 36(5):702-8.

12) Hakim Darail NA, Lee SH, Kang SW, Jeong JJ, Nam KH, Chung WY. Gasless transaxillary endoscopic thyroidectomy: a decade on. Surg Laparosc Endosc Percutan Tech 2014;24(6):e211-5.

13) Im HJ, Koo DH, Paeng JC, Lee KE, Chung YS, Lim I, et al. Evaluation of surgical completeness in endoscopic thyroidectomy compared with open thyroidectomy with regard to remnant ablation. Clin Nucl Med 2012;37(2):148-51.

14) Lee S, Lee CR, Lee SC, Park S, Kim HY, Son H, et al. Surgical completeness of robotic thyroidectomy: a prospective comparison with conventional open thyroidectomy in papillary thyroid carcinoma patients. Surg Endosc 2013;28(4):1068-75.

15) Tae K, Song CM, Ji YB, Kim KR, Kim JY, Choi YY. Comparison of surgical completeness between robotic total thyroidectomy versus open thyroidectomy. Laryngoscope 2014;124(4):1042-7.

16) Choe JH, Kim SW, Chung KW, Park KS, Han W, Noh DY, et al. Endoscopic thyroidectomy using a new bilateral axillo-breast approach. World J Surg 2007;31(3):601-6.

17) Tan CT, Cheah WK, Delbridge L. "Scarless" (in the neck) endoscopic thyroidectomy (SET): an evidence-based review of published techniques. World J Surg 2008;32(7):1349-57.

18) Salvatori M, Raffaelli M, Castaldi P, Treglia G, Rufini V, Perotti G, et al. Evaluation of the surgical completeness after total thyroidectomy for differentiated thyroid carcinoma. Eur J Surg Oncol 2007;33(5): 648-54.

19) Erbil Y, Barbaros U, Salmaslioglu A, Issever H, Tukenmez M, Adalet I, et al. Determination of remnant thyroid volume: comparison of ultrasonography, radioactive iodine uptake and serum thyroidstimulating hormone level. J Laryngol Otol 2008;122(6):615-22.

20) Schlumberger M, Catargi B, Borget I, Deandreis D, Zerdoud S, Bridji $\mathrm{B}$, et al. Strategies of radioiodine ablation in patients with low-risk thyroid cancer. N Engl J Med 2012;366(18):1663-73.

21) Lee KE, Koo do H, Im HJ, Park SK, Choi JY, Paeng JC, et al. Surgical completeness of bilateral axillo-breast approach robotic thyroidectomy: comparison with conventional open thyroidectomy after propensity score matching. Surgery 2011;150(6):1266-74. 